\title{
Impact of communicating personalized genetic risk information on perceived control over the risk: A systematic review
}

\author{
Ruth E. Collins, $\mathrm{MSc}^{1}$, Alison J. Wright, PhD ${ }^{2}$, and Theresa M. Marteau, PhD, FMedSci ${ }^{1}$
}

\begin{abstract}
Purpose: Much concern has been expressed that feedback of personalized genetic risk information may lead to fatalism, i.e., a lack of perceived control over the risk. This review aimed to assess the strength of evidence for such a view. Method: Electronic databases were searched to find eligible studies, which comprised randomized, controlled trials and analog studies, in which participants in one arm received either real or imagined personalized genetic risk information and assessed perceived control in relation to the treatability or preventability of the health problem. Results: Inspection of 1340 abstracts resulted in 5 studies meeting the inclusion criteria, involving the prediction of obesity, heart disease, depression, and diabetes. Meta-analyses of the clinical studies revealed no impact of personalized genetic risk information on perceived control in either the short term (pooled standardized mean difference $0.09,95 \%$ confidence interval, -0.51 to 0.70 ) or longer term (pooled standardized mean difference 0.00 , confidence interval, -0.20 to 0.21 ). Similarly, no impact on perceived control was evident in the three analog studies (pooled standardized mean difference 0.02 , confidence interval, -0.17 to 0.20 ). Conclusion: Few studies have assessed empirically the impact of personalized genetic risk information on fatalism, assessed using perceptions of control over the risk. Limited evidence suggests feedback of genetic risk information may have little impact on such beliefs. Genet Med 2011: 13(4):273-277.
\end{abstract}

Key Words: fatalism, perceived control, genetic screening, genetic prediction, health behavior

$\mathrm{D}$ NA-based profiling for disease risk is becoming increasingly common. Communicating the results of such testing may encourage health-promoting behaviors including screening uptake, medication adherence, and adoption of risk-reducing behaviors. Such behavioral change is predicted by beliefs concerning the health consequences of changing behavior and perceived level of control over the health risk. ${ }^{1-3}$

Genetic causes, compared with other causes of disease, are generally perceived as more serious and uncontrollable. ${ }^{4,5}$ Thus, there is concern that the feedback of genetic status may precipitate feelings of fatalism, i.e., feelings of no or low control over the health risk, in those found to have an elevated risk of developing a particular disease. ${ }^{6}$ There is also a concern that

From the ${ }^{1}$ Health Psychology Section and ${ }^{2}$ Department of Public Health Sciences, King's College London, London, United Kingdom.

Theresa M. Marteau, PhD, FMedSci, Health Psychology Section, Department of Psychology, King's College London, 5th Floor Bermondsey Wing, Guy's Campus, London SE1 9RT, United Kingdom. E-mail: theresa. marteau@kcl.ac.uk.

Disclosure: The authors declare no conflicts of interest.

Submitted for publication May 11, 2010.

Accepted for publication August 12, 2010.

Published online ahead of print October 1, 2010.

DOI: $10.1097 /$ GIM.0b013e3181f710ca feedback of results indicating a nonelevated risk of developing a particular disease may engender a sense of false reassurance, which too may discourage behavior change. ${ }^{7}$

However, communication of genetic risk information is not inextricably linked to fatalism, ${ }^{8-10}$ although it may influence perceptions of treatment efficacy. ${ }^{11}$ Several studies suggest that rather than changing individuals' overall perceptions of their control over a health threat, genetic risk information may change beliefs about the optimal treatment to control the problem. Risk assessments derived from analysis of genetic material increase the perceived effectiveness of medication to deal with the problem. ${ }^{11}$ This has been documented for depression, heart disease, and stopping smoking. ${ }^{12-16}$ Therefore, it may be that individuals are not discouraged in their ability to control outcomes per se but select different prevention or treatment options on the basis of differential perceived effectiveness.

The primary aim of this review is to estimate the impact of feedback of personalized genetic risk information on fatalism, operationalized using perceived control over the preventability and/or treatability of disease. The secondary aim is to assess the impact of genetic risk information on the perceived effectiveness of different types of prevention or treatment. The results of this review are intended to inform the design and implementation of strategies to communicate genetic risk information to achieve maximum motivational impact.

\section{METHODS}

We used the Cochrane Review handbook to guide the methods used in conducting this review. ${ }^{16}$

\section{Data sources and searches}

An electronic database search was conducted using MEDLINE (1950 to present), EMBASE (1980 to present), PsycINFO (1806 to present), and AMED (1985 to present) using OVID SP and PubMed, web of knowledge, and the Cochrane central registry for clinical trials (CENTRAL, the Cochrane Library). The search strategy for MEDLINE is presented in Appendix. This search strategy was tailored as necessary for other databases (details available on request). Reference list and forward citation searches for all potentially eligible studies were also conducted. Study selection was not restricted by language.

The initial search yielded 1340 abstracts, which were reviewed by 2 independent authors, resulting in 30 articles that, on the basis of abstract alone, seemed to meet the review inclusion criteria. Of these 30 articles, 6 met the eligibility criteria based on an inspection of the full text. Data were unavailable for one study, despite requests from the authors, resulting in five studies being included in the review (Fig. 1).

\section{Study selection}

Studies considered eligible for the review were randomized, controlled trials and analog studies in which participants in one arm received either real or imagined personalized genetic risk 


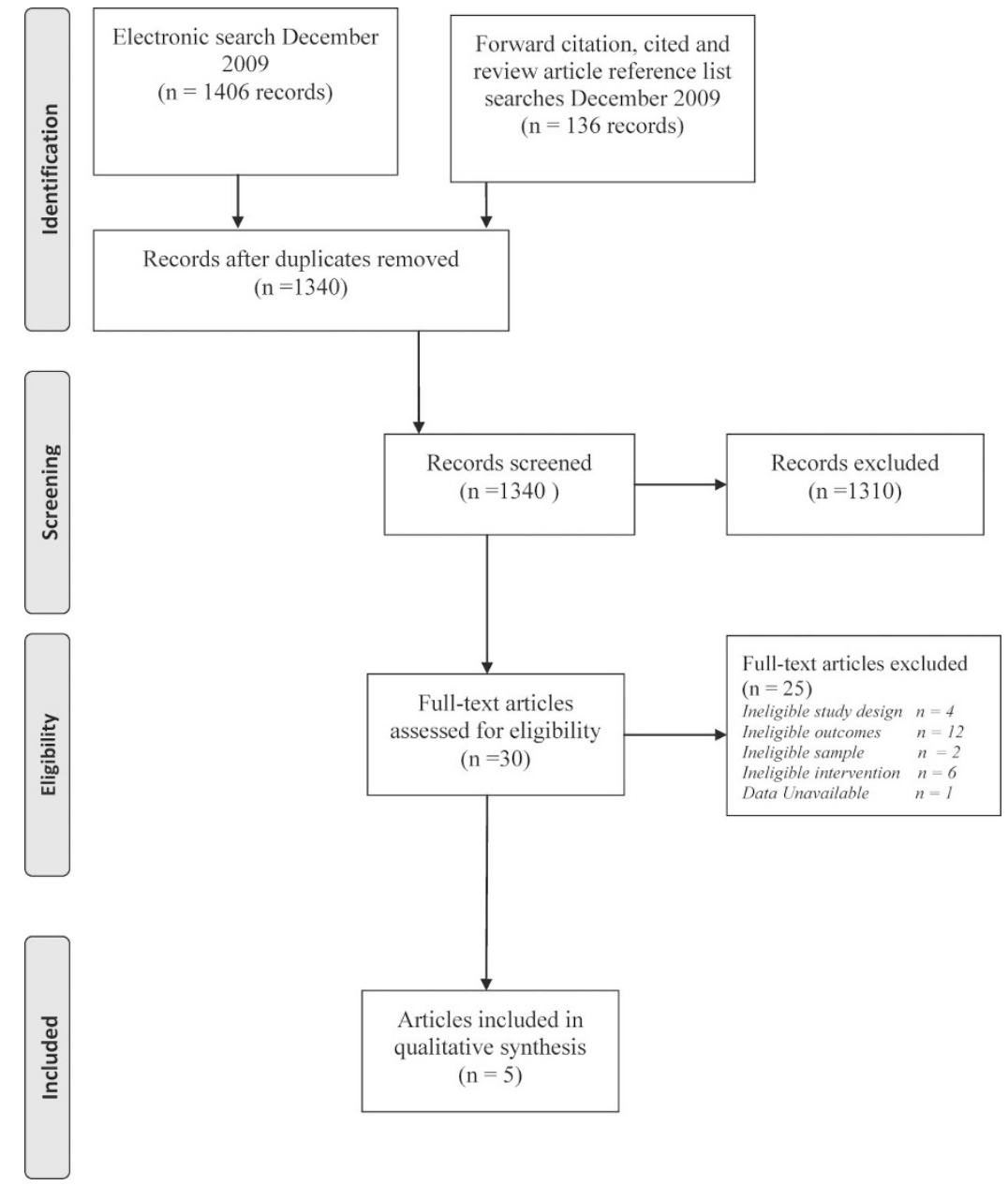

Fig. 1. Study selection flow through diagram.

information and within another arm did not. Eligible articles were also those that contained at least one measure of perceived control in relation to either the development or treatment of the health problem for which the genetic test had been conducted. This excluded studies communicating lung cancer risk information that measure perceived control over smoking ${ }^{17}$ rather than over the disease risk itself.

\section{Data extraction and quality assessment}

Data were extracted (R.E.C.) and independently checked (T.M.M.), with disagreements resolved by consensus. Variables of interest included study participants, study design (including number of arms), personalized genetic risk information (disease risk basis: DNA versus family history and disease type), and perceived control (measure and time points).

Risk of bias within the included studies was assessed by two authors in line with recommended principles. ${ }^{16}$ Elements assessed were randomization, i.e., evidence of true randomization procedures; allocation concealment, i.e., adequate if group allocation concealed from both researcher and participant before allocation; validation of measures, i.e., evidence of both reliability and validity of primary endpoint measures; comparability of groups at baseline; and follow up, i.e., adequate if primary outcome data were reported on at least $80 \%$ of participants.

\section{Data synthesis and analyses}

The primary analysis involved comparisons between randomized arms on outcomes assessing perceived control. The secondary analysis involved comparing randomized arms on measures of perceived effectiveness of treatments. Results are presented separately for clinical and analog studies. Primary outcome measures regarded as comparable were pooled, i.e., merged, with effect sizes presented as standardized mean difference (SMD). Heterogeneity was assessed using the $I^{2}$ statistic. Outcomes assessed within 1 month of feedback of personalized genetic information were categorized as shortterm, and outcomes assessed at 1 month or longer after feedback of personalized genetic information were categorized as longer term.

\section{RESULTS}

\section{Characteristics of included studies}

Of the five included studies (Table 1), two were randomized controlled trials, ${ }^{13,18}$ and three were analog studies (Wright et al., unpublished study). ${ }^{17-19}$ Two studies assessed perceived control over the development of obesity; a further two measured perceived control over multiple disease types, and one as- 
Table 1 Characteristics of included studies

\begin{tabular}{|c|c|c|c|c|}
\hline & Design & $\begin{array}{l}\text { Personalized } \\
\text { genetic risk }\end{array}$ & Health problem & Perceived control measure \\
\hline Marteau et al. ${ }^{13}$ & Clinical & DNA & $\begin{array}{l}\text { Heart disease familial } \\
\text { hypercholesterolemia } \\
\text { (FH) cholesterol }\end{array}$ & $\begin{array}{l}\text { Perceived control over FH was taken from the revised } \\
\text { Illness Perception Questionnaire. }{ }^{21} \text { Perceived control } \\
\text { over cholesterol/heart disease, developed in a pilot." }\end{array}$ \\
\hline Pijl et al. ${ }^{18}$ & Clinical & Family history & Diabetes & "There is a lot I can do to prevent getting diabetes" \\
\hline Frosch et al. ${ }^{19}$ & Analogue & DNA & Obesity & $\begin{array}{l}\text { "Eating a healthy diet in the next } 3 \text { months will help me } \\
\text { not become overweight or obese" }\end{array}$ \\
\hline $\begin{array}{l}\text { Wright et al., } \\
\text { unpublished study }\end{array}$ & Analogue & $\begin{array}{l}\text { DNA and family } \\
\text { history }\end{array}$ & $\begin{array}{l}\text { Heart disease } \\
\text { Obesity } \\
\text { Depression }\end{array}$ & $\begin{array}{l}\text { "How much control do you think Sam had over the } \\
\text { development of his problem?" }\end{array}$ \\
\hline Sanderson et al. ${ }^{20}$ & Analogue & DNA & Obesity & $\begin{array}{l}\text { Diet self-efficacy was assessed with three items: "I would } \\
\text { like to eat a healthy diet but I don't know if I can," "I } \\
\text { am confident that if I tried to eat a healthy diet in the } \\
\text { next } 3 \text { months I could keep to it," and "I am confident } \\
\text { that I could eat a healthy diet if I wanted to." }\end{array}$ \\
\hline
\end{tabular}

sessed perceived control over the development of diabetes. The 5 included studies involved 1518 participants with a mean age of 42.2 years. The gender mix among study participants ranged from $51 \%$ to $70 \%$ women.

\section{Quality assessment of included studies}

Data were pooled for studies reporting the same primary outcome, i.e., a measure of perceived control in relation to the health problem. This was done separately for clinical and analog studies. The primary comparison was between randomized groups, i.e., those receiving personalized genetic risk information and those not receiving personalized genetic risk information.

\section{Perceived control}

\section{Clinical studies}

Two studies ${ }^{13,18}$ assessed the impact of personalized genetic risk information on perceived control of health problems in the short-term (Fig. 2). The pooled SMD was 0.09 (95\% confidence interval $[\mathrm{CI}],-0.51$ to 0.70$)$, indicating no impact of personalized genetic risk information on perceived control at $<4$ weeks. However, interpretation of results should be undertaken with some caution, given the high level of heterogeneity of included studies $\left(I^{2}=86 \%\right)$.

The same two studies ${ }^{13,18}$ also assessed the impact of personalized genetic risk information on perceived control of health problems at $>4$ weeks after the information was communicated. The pooled SMD was 0.00 (95\% CI, -0.20 to 0.21 ), indicating no effect of personalized genetic risk information on perceived control detectable in the longer term.

\section{Analog studies}

Three studies (Wright et al., unpublished study) $)^{19,20}$ assessed the impact of imagined personalized genetic risk information on perceived control over the development of the health problem.

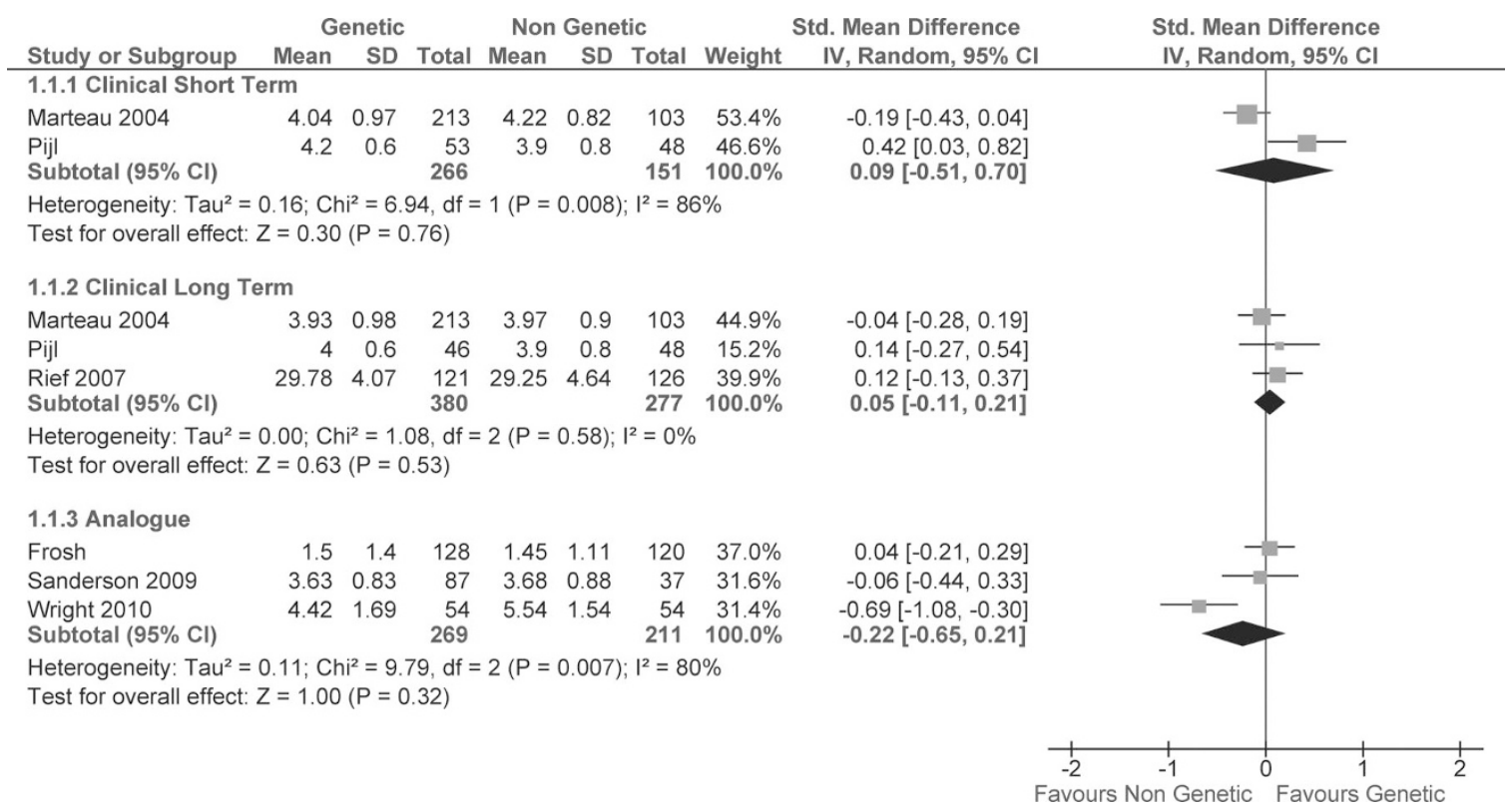

Fig. 2. Impact of personalized risk information on perceived control. 
The pooled SMD was -0.22 (95\% CI, -0.65 to 0.21$)$, indicating no impact of imagined personalized genetic risk information on perceived control. However, the high level of heterogeneity of included studies $\left(I^{2}=80 \%\right)$ means that interpretations of results should be treated cautiously. No data were available to assess the impact of personalized genetic risk information in the longer term.

\section{Perceived effectiveness}

\section{Clinical studies}

Only one study assessed the impact of personalized genetic risk information on the perceived effectiveness of behavioral interventions at $<4$ weeks. ${ }^{13}$ The SMD was 0.05 (95\% CI, -0.19 to 0.28 ), indicating no impact of personalized genetic risk information on the perceived effectiveness of behavioral interventions.

Only one study assessed the impact of personalized genetic information on perceived effectiveness of medical interventions in the short-term. ${ }^{13}$ The SMD was 0.03 (95\% CI, -0.20 to 0.27 ), indicating no impact of personalized genetic risk on the perceived effectiveness of medical interventions at $<4$ weeks.

\section{Analog studies}

Three studies evaluated the impact of imagined personalized genetic information on perceived effectiveness of behavioral interventions (Wright et al., unpublished study). ${ }^{19,20}$ The pooled SMD was $0.02(95 \% \mathrm{CI},-0.17$ to 0.20$)$, indicating no adverse effects of personalized genetic risk on perceived effectiveness of behavioral interventions.

Only one study assessed the impact of imagined personalized genetic information on perceived effectiveness of medical interventions (Wright et al., unpublished study). The SMD was 0.40 (95\% CI, 0.01 to 0.78$)$, indicating a small effect of personalized genetic risk on perceived effectiveness of medical interventions with greater levels of perceived effectiveness within the group receiving personalized genetic information.

\section{DISCUSSION}

Few studies were deemed eligible for the review. The limited evidence available revealed no impact of personalized genetic information on perceived control. Personalized genetic risk information had no impact on the perceived effectiveness of behavioral interventions. Only one study assessed the impact of personalized genetic information on perceived effectiveness of medication, revealing a small effect.

The results of this review stand in contrast with the widespread belief that the communication of genetic risk information may lower perceived control over health outcomes. This lack of an effect on perceived control may be explained in the context of theories of self-regulation of behavior, which describe the ways in which individuals respond to threats in ways that allow core goals to be maintained. ${ }^{22}$ Such responses include the use of cognitive and behavioral strategies aimed at reducing the potential threat by, e.g., minimization and taking action to reduce a threat. Although initial responses to health risk information may elicit anxiety and concerns about loss of control, rarely are such effects enduring. ${ }^{23}$ This reflects the powerful motivation in humans to perceive control over their fates. ${ }^{24,25}$ When new information challenges the extent to which people can control their environments, they are adept at retaining control by altering their perceptions to fit their environment. ${ }^{26}$ When the risk is not modifiable, as is the case for Huntington disease, learning of the presence of the gene for this dominantly inherited condition does not result in depression, associated with a loss of control, in the few who undergo such testing, ${ }^{27}$ but rather seems to confer a sense of what has been termed secondary control in allowing the future to be predicted. Similar findings have been reported for predictive genetic testing for Alzheimer disease. ${ }^{28}$ When the risk is modifiable, personalized genetic risk information seems to alter individuals' appraisals of treatment effectiveness rather than their perceptions of control. ${ }^{11}$ Future studies can be designed to investigate these predicted effects in addition to potential effect modifiers. These might include the nature of the condition for which testing is being offered, the type of behavior that is the target for risk reduction, and the characteristics of the study population.

Owing to the significant heterogeneity of studies included in the assessment of perceived control, interpretation of results should be undertaken with some caution. Included studies varied a great deal in the test methods used, the health problem for which individuals were tested, and the arms into which participants were randomized. Two of the studies used nonvalidated measures to assess perceived control and two reported on multiple disease types. Furthermore, the mode of genetic assessment within this study varied between family history, DNA analyses, and a combination of both. These assessments may impact differentially on individuals. It is possible that DNA analysis may be regarded as more salient than family history and, thus, may lead to a greater psychological distress (Wright et al., unpublished study).

The strength of this review lies in its novelty, being the first, to the authors' knowledge, to empirically review the evidence for the prediction that communicating personalized genetic risk information leads to fatalism. However, the review is limited by the paucity of studies meeting the eligibility criteria. Although there is a vast literature on this topic, few studies have used randomized designs to compare the impact of communicating genetic risk information as opposed to nongenetic or no risk information. Even fewer studies have incorporated measures of perceived control. Although only five studies were found that met the eligibility criteria, we are aware of one ongoing relevant study (ISRCTN20442834).

In summary, the results of this review provide no evidence to suggest that communicating personalized genetic risk information engenders feelings of fatalism. Data from one study indicated that genetic risk information may alter individuals' appraisals of treatment efficacy. Future studies would benefit from the inclusion of both perceived control and perceived effectiveness measures to evaluate this relationship more fully, in addition to other recommendations for improving the quality of evidence regarding the emotional, cognitive, and behavioral impact of communicating genetic risk information. ${ }^{29,30}$

\section{ACKNOWLEDGMENTS}

This review was funded as part of a grant from the Medical Research Council, United Kingdom (Risk communication in preventative medicine: Optimising the impact of DNA risk information MRC ref.G0500274; PI: Theresa Marteau).

\section{REFERENCES}

1. Milne S, Sheeran P, Orbell S. Prediction and intervention in health-related behavior: a meta-analytic review of protection motivation theory. $J$ Appl Soc Psychol 2000;30:106-143.

2. Roesch SC, Weiner B. A meta-analytic review of coping with illness: do causal attributions matter? J Psychosom Res 2001;50:205-219.

3. Reed GM, Kemeny ME, Taylor SE, Visscher B. Negative HIV specific expectancies and AIDS-related bereavement as predictors of symptom onset in asymptomatic HIV-positive gay men. Health Psychol 1999;18:354-363.

4. Lam DC, Salkovskis PM, Warwick HM. An experimental investigation of 
the impact of biological versus psychological explanations of the cause of "mental illness." J Ment Health 2005;14:453-464.

5. Shiloh S, Rashuk-Rosenthal D, Benyamini Y. Illness causal attributions: an exploratory study of their structure and associations with other illness cognitions and perceptions of control. J Behav Med 2002;25:373-394.

6. McClure J. Are biomarkers useful treatment aids for promoting health behavior change? An empirical review. Am J Prev Med 2002;22:200-207.

7. Chapman E, Bilton D. Patients' knowledge of cystic fibrosis: genetic determinism and implications for treatment. J Genet Couns 2004;13:369-385.

8. Harvey-Berino J, Gold EC, West DS, et al. Does genetic testing for obesity influence confidence in the ability to lose weight? A pilot investigation. $J$ Am Diet Assoc 2001;101:1351-1353.

9. Hicken B, Tucker D. Impact of genetic risk feedback: perceived risk and motivation for health protective behaviors. Psychol Health Med 2002;7:25-36.

10. Lerman C, Gold K, Audrain J, et al. Incorporating biomarkers of exposure and genetic susceptibility into smoking cessation treatment: effects on smoking-related cognitions, emotions, and behavior change. Health Psychol 1997;16:87-99.

11. Marteau TM, Weinman J. Self-regulation and the behavioural response to DNA risk information: a theoretical analysis and framework for future research. Soc Sci Med 2006;62:1360-1368.

12. Iselin MG, Addis ME. Effects of etiology on perceived helpfulness of treatments for depression. Cognit Ther Res 2003;27:205-222.

13. Marteau T, Senior V, Humphries SE, et al; Genetic Risk Assessment for FH Trial Study Group. Psychological impact of genetic testing for familial hypercholesterolemia within a previously aware population: a randomized controlled trial. Am J Med Genet A 2004;128A:285-293.

14. Phelan JC, Yang LH, Cruz-Rojas R. Effects of attributing serious mental illnesses to genetic causes on orientations to treatment. Psychiatr Serv 2006;57:382-387.

15. Wright AJ, Weinman J, Marteau TM. The impact of learning of a genetic predisposition to nicotine dependence: an analogue study. Tob Control $2003 ; 12: 227-230$.

16. Higgins JP, Green SE. Cochrane Handbook for Systematic Reviews of Interventions version 5.0.1 (updated September 2008). The Cochrane Collaboration 2008. Available at: www.cochrane-handbook.org. Accessed June $1,2010$.

17. Sanderson SC, Michie S. Genetic testing for heart disease susceptibility: potential impact on motivation to quit smoking. Clin Genet 2007;71:501-510.

18. Pijl M, Timmermans DR, Claassen L. Impact of communicating familial risk of diabetes on illness perceptions and self-reported behavioral outcomes: a randomized controlled trial. Diabetes Care 2009;32:597-599.

19. Frosch DL, Mello P, Lerman C. Behavioral consequences of testing for obesity risk. Cancer Epidemiol Biomarkers Prev 2005;14:1485-1489.

20. Sanderson SC, Persky S, Michie S. Psychological and behavioral responses to genetic test results indicating increased risk of obesity: does the causal pathway from gene to obesity matter? Public Health Genomics 2010;13:34-47.

21. Moss-Morris R, Weinman J, Petrie KJ, Horne R, Cameron LD, Buick D. The revised Illness Perception Questionnaire (IPQ-R). Psychol Health 2002;17: $1-16$.

22. Carver CS, Scheier MF. Goals and behavior. On the self-regulation of behavior. Cambridge, United Kingdom: Cambridge University Press, 1998: 63-82.

23. Shaw C, Abrams K, Marteau TM. Psychological impact of predicting indi- viduals' risks of illness: a systematic review. Soc Sci Med 1999;49:15711598 .

24. Malinowski B. Magic, science, and religion. New York, NY: Anchor Books, 1955.

25. De Charms R. Personal causation. New York, NY: Academic Press, 1968.

26. Rothbaum F, Weisz JR, Snyder SS. Changing the world and changing the self: a two-process model of perceived control. J Pers Soc Psychol 1982;42:5-37.

27. Broadstock M, Michie S, Marteau T. Psychological consequences of predictive genetic testing: a systematic review. Eur J Hum Genet 2000;8:731-738.

28. Brown T, Roberts JS, LaRusse SA, et al. Impact of genetic risk assessment for Alzheimer's disease. J Genet Couns 2002;11:446-447.

29. McBride CM, Bowen D, Brody LC, et al. Future health applications of genomics: priorities for communication, behavioral, and social sciences research. Am J Prev Med 2010;38:556-565.

30. McBride CM, Koehly LM, Sanderson SC, Kaphingst KA. The behavioral response to personalized genetic information: will genetic risk profiles motivate individuals and families to choose more healthful behaviors? Annu Rev Public Health 2010;31:89-103.

\section{APPENDIX: MEDLINE SEARCH STRATEGY}

1. genetic services/

2. genetic screening/

3. genetic counseling/

4. genetic predisposition to disease/

5. Or/1-4

6. ( (gene or genes or genetic $\$$ or genotype $\$$ ) adj3 (test $\$$ or assess $\$$ or risk\$ or susceptibility or disease\$ or screen\$)).ti,ab.

7. counseling/or directive counseling/

8. (consult $\$$ or assess $\$$ or support $\$$ or inform $\$$ or advise $\$$ or advice or counsel\$ or educat $\$$ or share $\$$ or communicat $\$$ or teach\$ or discuss\$ or decide\$ or decision\$).ti,ab.

9. patient education as topic/

10. Or/7-9

11. 6 and 10

12. 5 or 11

13. (perceive $\$$ adj3 control\$).mp.

14. control belief $\$ . m p$.

15. controllab\$.mp.

16. ((perceive\$ or percep\$) adj3 (effectiveness or risk\$ or susceptibility)).mp.

17. Or/13-16

18. 12 and 17

See Higgins et al. ${ }^{16}$ for interpretation of terms used in search strategies. 